\title{
Tigecycline Versus Levofloxacin in Hospitalized Patients With Community-Acquired Pneumonia: An Analysis of Risk Factors
}

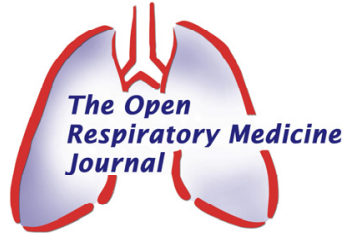

\author{
Nathalie Dartois ${ }^{*}, 1$, C. Angel Cooper ${ }^{2}$, Nathalie Castaing ${ }^{1}$, Hassan Gandjini ${ }^{1,+}$ \\ and Denise Sarkozy ${ }^{2, \dagger}$ on behalf of the 308 and 313 Study Groups
}

\author{
${ }^{1}$ Pfizer Global Research and Development, Paris, France \\ ${ }^{2}$ Pfizer Inc, Collegeville, PA, USA
}

\begin{abstract}
Introduction: This study was conducted to evaluate the efficacy of tigecycline (TGC) versus levofloxacin (LEV) in hospitalized patients with community-acquired pneumonia (CAP) using pooled data and to perform exploratory analyses of risk factors associated with poor outcome.
\end{abstract}

\begin{abstract}
Materials and Methodology: Pooled analyses of 2 phase 3 studies in patients randomized to intravenous (IV) TGC $(100 \mathrm{mg}$, then $50 \mathrm{mg} \mathrm{q} 12 \mathrm{~h})$ or IV LEV $(500 \mathrm{mg} \mathrm{q} 24 \mathrm{~h}$ or $\mathrm{q} 12 \mathrm{~h})$. Clinical responses at test of cure visit for the clinically evaluable (CE) and clinical modified intention to treat populations were assessed for patients with risk factors including aged $\geq 65$ years, prior antibiotic failure, bacteremia, multilobar disease, chronic obstructive pulmonary disease, alcohol abuse, altered mental status, hypoxemia, renal insufficiency, diabetes mellitus, white blood cell count $>30 \times 10^{9} / \mathrm{L}$ or $<4 \times 10^{9} / \mathrm{L}$, CURB-65 score $\geq 2$, Fine score category of III to $\mathrm{V}$ and at least 2 clinical instability criteria on physical examination.

Results: In the CE population of 574 patients, overall cure rates were similar: TGC (253/282, 89.7\%); LEV (252/292, $86.3 \%$ ). For all but one risk factor, cure rates for TGC were similar to or higher than those for LEV. For individual risk factors, the greatest difference between treatment groups was observed in patients with diabetes mellitus (difference of 22.9 for TGC versus LEV; 95\% confidence interval, 4.8 - 39.9).

Conclusions: TGC achieved cure rates similar to those of LEV in hospitalized patients with CAP. For patients with risk factors, TGC provided generally favorable clinical outcomes.
\end{abstract}

Keywords: Community-acquired pneumonia, glycylcycline, risk factors, tigecycline.

\section{INTRODUCTION}

Community-acquired pneumonia (CAP) is the cause of 500,000 to 1 million hospital admissions each year in the United States [1]. Associated with high morbidity and mortality, CAP requiring hospitalization also is the most frequent serious infection that clinicians treat worldwide [1$3]$. The challenge of treating patients with CAP has been heightened by the emergence of antibiotic-resistant bacteria including multidrug-resistant Streptococcus pneumonia [4,5], methicillin-resistant Staphylococcus aureus and community-associated methicillin-resistant $S$. aureus [6]. Pathogens frequently implicated in CAP include macrolideresistant and penicillin-resistant pneumococci, Haemophilus influenzae and other potentially resistant pathogens.

Response to appropriate antibiotic treatment may be influenced by various underlying and interrelated patient-

*Address correspondence to this author at Pfizer Global Research and Development, 23-25 avenue du Docteur Lannelongue, 75668 Paris Cedex 14, France; Tel: + 331580734 31; E-mail: nathalie.dartois@pfizer.com

${ }^{\dagger}$ Former employee of Pfizer Inc. specific factors including advanced age $[7,8]$, male gender [7-9], severity of infection, compromised immune status [10] and coexisting disease conditions such as chronic cardiovascular or respiratory disease, diabetes mellitus and neoplasm [7-9]. Patients with malnutrition [7], suspicion of aspiration [7], altered mental status [7-9], low blood pressure $[7,9]$, tachypnea [7,9], hypothermia (i.e., temperature lower than $35^{\circ} \mathrm{C}$ ) [7,9], high blood urea nitrogen [7] and multilobar radiographic pulmonary infiltrates $[7,9]$ represent other highrisk categories indicative of a negative outcome. Accordingly, the Fine pneumonia severity index and the CURB-65 scoring systems were developed to help clinicians identify the mortality risk for patients with CAP to help guide treatment decisions [11,12]. A thorough assessment for CAP-associated prognostic factors allows the clinician to make appropriate decisions on the management for the patient.

Tigecycline (TGC), a novel glycylcycline antibiotic, overcomes 2 key tetracycline resistance mechanisms (efflux pumps and ribosomal protection) [13] and has in vitro activity against a broad spectrum of gram-positive and gramnegative bacteria, atypical organisms, anaerobes and multidrug-resistant pathogens $[13,14]$. The efficacy and 
safety of TGC have been demonstrated in randomized, double-blind, controlled phase 3 studies, and TGC has received regulatory approval for the treatment of complicated intra-abdominal infections and complicated skin and skin structure infections in over 65 countries $[15,16]$. More recently, TGC has been approved in some countries for the treatment of community-acquired bacterial pneumonia.

Levofloxacin (LEV), a synthetic, broad-spectrum fluoroquinolone, is one of several standard therapies recommended for the treatment of patients with CAP $[1,3,17,18]$. The present report presents an exploratory analysis of data from 2 previously published phase 3 studies [19] that compared the overall efficacy and safety of TGC with those of LEV in the treatment of hospitalized patients with CAP and evaluates clinical response to treatment by prognostic risk factors. In this post hoc analysis, we provide additional detail from the previously published data that highlights clinical responses at test of cure (TOC) visit as it relates to risk factors associated with a poor outcome.

\section{MATERIALS AND METHODOLOGY}

\section{Study Design}

This exploratory analysis of prognostic risk factors in hospitalized patients with CAP utilized pooled data from 2 phase 3, multicenter, randomized, double-blind studies (308 and 313) [19]. Study 308 was conducted in the United States, Canada and Latin America; study 313 in Europe, Asia Pacific and South Africa. At randomization, patients were stratified by geographic location (study 308) and Fine score category (both studies) [19] and then assigned to TGC or LEV. Each protocol was reviewed and approved by each investigator's independent ethics committee or institutional review board in accordance with local regulations and good clinical practices. Written informed consent was obtained from each patient or his/her guardian before the initiation of any study procedures.

The primary efficacy endpoint in the original pooled analysis was clinical response within the clinically evaluable (CE) and clinical modified intention to treat (c-mITT) populations at the TOC assessment 7 to 23 days post therapy [19]. Using the same patient populations, clinical response (cure/failure/indeterminate outcome) in the present analysis was evaluated by prognostic risk factors. Specific risk factors analyzed included patients with the following characteristics: aged $\geq 65$ years $[7,8]$, prior antibiotic failure [20], bacteremia [9], multilobar disease at baseline [7,9], chronic obstructive pulmonary disease (COPD) [21], hypoxemia [11], renal insufficiency or blood urea nitrogen $>20 \mathrm{mg} / \mathrm{dL}$ or urea $>7 \mathrm{mmol} / \mathrm{L}$ [7], diabetes mellitus or baseline glucose $>13.9 \mathrm{mmol} / \mathrm{L}$ [9], alcohol abuse [22], altered mental status [7-9], white blood cell (WBC) count $>30 \times 10^{9} / \mathrm{L}$ or $<4 \times 10^{9} / \mathrm{L}, \mathrm{CURB}-65$ score $\geq 2$ (post-study calculation) [12] and Fine score category of III to $\mathrm{V}$ [11]. Data were presented for patients with at least 2 clinical instability criteria (i.e., oral temperature $>37.8^{\circ} \mathrm{C}$, heart rate $>100$ beats per minute, respiratory rate $>24$ breaths $/ \mathrm{min}$, systolic blood pressure $<90 \mathrm{~mm} \mathrm{Hg}$, hypoxemic, WBC count $>11 \times 10^{9} / \mathrm{L}$ and altered mental status). The clinical instability criteria were the opposite of the clinical stability criteria suggested by Menendez et al. [23], or the opposite of criteria that would allow patients to be switched to oral medication or discharged [24]. In addition, a pooled analysis of the efficacy and mortality in the group at higher risk for mortality (i.e., aged $\geq 50$ years, Fine score category of III to $\mathrm{V}$ or bacteremia due to $S$. pneumoniae) was conducted.

In this exploratory analysis, categorical baseline demographic, medical and risk factor variables were analyzed using the Fisher exact test. Continuous variables were analyzed using a one-way analysis of variance model with treatment as a factor. Clinical response rates by the presence of prognostic risk factors were analyzed between treatment groups using 95\% confidence intervals (CIs) for differences, calculated using the Wilson score method.

\section{Treatment Regimens}

In the 2 original CAP studies, patients were assigned in a $1: 1$ double-blind fashion to receive either intravenous (IV) TGC (an initial 100-mg dose given by infusion over a 30-60 minute period, followed by $50 \mathrm{mg}$ IV every 12 hours) or LEV (500 mg once daily or every 12 hours, based on the investigator's discretion, administered over approximately 60 minutes; for patients with creatinine clearance 20-49 $\mathrm{mL} / \mathrm{min}$, the dose was to be $250 \mathrm{mg}$ once or twice daily) [19]. Patients in one study (313) were to receive at least 7 days of IV therapy, unless clinical failure occurred, up to a maximum of 14 days. In the second study (308), patients in both treatment groups were allowed to switch to oral LEV after at least 3 days of IV dosing if they met protocolspecified criteria for improvement in the signs and symptoms of pneumonia. Treatment was to be administered for a minimum of 7 total days (IV plus oral) to a maximum of 14 days of therapy overall.

\section{Primary Inclusion/Exclusion Criteria}

All patients with CAP in this risk factor analysis satisfied the following entry criteria per the original study protocols [19]. Male or non-pregnant/non-lactating female patients aged $\geq 18$ years hospitalized with clinical signs and symptoms of CAP who required initial parenteral therapy were considered for enrollment. Primary inclusion criteria included fever within 24 hours of randomization or hypothermia; at least 2 signs and symptoms consistent with CAP (e.g., cough, production of purulent or mucopurulent sputum, auscultatory findings on pulmonary examination suggestive of pulmonary consolidation; dyspnea or tachypnea; WBC count $>10,000 / \mathrm{mm}^{3}$ or hypoxemia); and radiologically confirmed evidence of a new or progressive infiltrate(s) consistent with bacterial pneumonia within 48 hours before receiving the first dose of study drug. Key exclusion criteria included hospitalization within 14 days before the onset of symptoms, Fine score category of V (study 308 only), required treatment in an intensive care unit and bronchiectasis or post-obstructive pneumonia or end-stage COPD (forced expiratory volume in 1 second $<30 \%$ predicted).

\section{Clinical Evaluations}

Patients comprising this risk factor analysis were evaluated and clinical signs and symptoms were recorded at serial visits: baseline (within 24 hours of first study drug dose), during treatment, early follow-up ( 2 - 4 days post therapy) and TOC ( 7 - 23 days post therapy). Pulse oximetry and/or arterial blood gases were obtained at baseline, end of 
IV therapy, early follow-up and at TOC visits. Chest x-rays were obtained at baseline (within 48 hours of receiving the first dose of study drug) and were repeated at the TOC visit. At baseline, respiratory tract specimens, blood cultures and serum for serology were obtained whenever possible; Legionella and pneumococcal urinary antigens and rapid influenza tests also were performed. Tests were conducted using commercially available kits to local standards. Serology testing was performed by a central laboratory to Clinical Laboratory Standards Institute standards. Clinical responses were graded as cure, failure or indeterminate outcome at the TOC assessment [19].

\section{RESULTS}

In the previously published pooled analysis, a total of 574 patients (TGC, 282; LEV, 292) and 797 patients (TGC, 394; LEV, 403) comprised the CE and c-mITT populations, respectively [19]. These patient populations were the focus of the present exploratory analysis of efficacy by risk factor subgroups. Tigecycline-treated patients and levofloxacintreated patients were similar in demographics and baseline medical characteristics in the modified intention to treat population (Table 1). The population was predominantly male $(\sim 60 \%)$ with a mean age of 52 years. Approximately

Table 1. Demographics and Baseline Characteristics for Pooled CAP Studies 308 and 313 (Modified Intention to Treat Population)

\begin{tabular}{|c|c|c|c|}
\hline Characteristic & Tigecycline $(n=424)$ & Levofloxacin $(n=422)$ & p-Value \\
\hline \multicolumn{4}{|l|}{ Age, Years } \\
\hline SD & 17.99 & 18.74 & \\
\hline Male, n (\%) & $243(57.3)$ & $265(62.8)$ & 0.107 \\
\hline Prior antibiotic failure & $62(14.6)$ & $74(17.5)$ & 0.262 \\
\hline Bacteremia & $32(7.5)$ & $31(7.3)$ & 1.000 \\
\hline Multilobar disease at baseline & $125(29.5)$ & $106(25.1)$ & 0.165 \\
\hline COPD & $49(11.6)$ & $43(10.2)$ & 0.581 \\
\hline Alcohol abuse & $35(8.3)$ & $33(7.8)$ & 0.899 \\
\hline Altered mental status & $9(2.1)$ & $9(2.1)$ & 1.000 \\
\hline WBC count $>30 \times 10^{9} / \mathrm{L}$ or $<4 \times 10^{9} / \mathrm{L}$ & $21(5.0)$ & $19(4.5)$ & 0.872 \\
\hline \multicolumn{4}{|l|}{ CURB-65 Score, n (\%) } \\
\hline Total score $\geq 2$ & $122(28.8)$ & $124(29.4)$ & 0.880 \\
\hline \multicolumn{4}{|l|}{ CURB-65 Score Components } \\
\hline Confusion (altered mental status from medical history) & $9(2.1)$ & $9(2.1)$ & 1.000 \\
\hline Urea $>7 \mathrm{mmol} / \mathrm{L}(\mathrm{BUN}>19.6 \mathrm{mg} / \mathrm{dL})$ & $129(30.4)$ & $125(29.6)$ & 0.822 \\
\hline Respiratory rate $\geq 30$ breaths $/ \mathrm{min}$ & $109(25.7)$ & $95(22.5)$ & 0.296 \\
\hline Oral temperature $>37.8^{\circ} \mathrm{C}$ & $381(89.9)$ & $384(91.0)$ & 0.641 \\
\hline Heart rate $>100 \mathrm{bpm}$ & $168(39.6)$ & $171(40.5)$ & 0.833 \\
\hline Respiratory rate $>24$ breaths $/ \mathrm{min}$ & $166(39.2)$ & $157(37.2)$ & 0.572 \\
\hline Systolic blood pressure $<90 \mathrm{~mm} \mathrm{Hg}$ & $11(2.6)$ & $13(3.1)$ & 0.685 \\
\hline Hypoxemia & $106(25.0)$ & $113(26.8)$ & 0.583 \\
\hline WBC count $>11 \times 10^{9} / \mathrm{L}$ & $231(54.5)$ & $235(55.7)$ & 0.730 \\
\hline Altered mental status & $9(2.1)$ & $9(2.1)$ & 1.000 \\
\hline
\end{tabular}


$29 \%$ of patients had estimated CURB-65 scores $\geq 2$, almost $47 \%$ of patients had a Fine score category of III to $\mathrm{V}$ and approximately $79 \%$ of patients had at least 2 clinical instability criteria.

\section{Clinical Response and Risk Factors}

For all but one of the evaluated risk factors, cure rates for TGC-treated patients were similar to or higher than those for LEV-treated patients in both the CE and c-mITT populations (Table 2). In the $\mathrm{CE}$ population, the greatest differences in cure rates between treatment groups in favor of TGC were observed for patients who had diabetes mellitus or a baseline serum glucose level $>13.9 \mathrm{mmol} / \mathrm{L}$ (TGC, 97.2\% vs LEV, $74.4 \%$ [difference of $22.9 ; 95 \%$ CI, 4.8 - 39.9]), followed by patients with bacteremia (TGC, 84.0\% vs LEV, $70.0 \%$ [difference of $14.0 ; 95 \% \mathrm{CI},-13.1$ - 40.6]) and prior antibiotic failure (TGC, $81.8 \%$ vs LEV, 70.0\% [difference of 11.8; 95\% CI, -26.3 - 40.4]). Levofloxacin-treated patients with altered mental status had a greater favorable difference in cure rate $(87.5 \%)$ compared with TGC-treated patients (71.4\%) (difference of -16.1 ; 95\% CI, -58.9 - 31.0), albeit this subgroup was populated with a low number of patients. Differences in cure rates between treatment groups were smaller for the other risk factors of aged $\geq 65$ years, multilobar disease, COPD, hypoxemia, renal insufficiency, alcohol use, WBC count $>30 \times 10^{9} / \mathrm{L}$ or $<4 \times 10^{9} / \mathrm{L}$, CURB65 score $\geq 2$, Fine score category of III to $\mathrm{V}$ and the presence of at least 2 instability criteria.

Cure rates within the risk factor subgroups were more consistent with the overall cure rates for TGC-treated patients than for LEV-treated patients in the CE population. For the c-mITT population, relationship to the overall cure rate was generally similar for the 2 treatment groups. In the population of patients considered at higher risk for mortality, cure rates remained consistent with the overall cure rates and were numerically higher for TGC-treated patients than for LEV-treated patients in both the CE and c-mITT populations.

Overall, the number of deaths in the 2 studies was similar between the 2 treatment groups: 12 TGC-treated patients (2.8\%) versus $11 \mathrm{LEV}$-treated patients $(2.6 \%)$, with none of the adverse events resulting in death considered by the investigator to be related to study drug. Mortality rates categorized by individual risk factor were comparable between the 2 treatment groups (Table 3). In the subgroup of patients at higher risk for mortality, a similar number of deaths occurred in each treatment group (12 TGC, 10 LEV).

\section{DISCUSSION}

This exploratory analysis of 2 pivotal, phase 3 , doubleblind clinical trials found that among hospitalized patients with CAP, cure rates across prognostic factors known to influence clinical outcome, including age, underlying medical comorbidities, pneumonia characteristics and pneumonia severity index, were more consistent with the overall cure rate for TGC-treated patients than for LEVtreated patients in the $\mathrm{CE}$ population. Although overall clinical cure rates were similar between $\mathrm{CE}$ patients randomized to IV TGC or IV LEV (approximately 90\% and $86 \%$, respectively), patients treated with TGC had numerically higher cure rates and tended to achieve better cure rates within some risk factor subgroups. Patients treated with TGC who were considered at higher risk for mortality had numerically higher cure rates than similar patients treated with LEV.

In the CE population, the greatest difference in favor of TGC was observed for patients with a history of diabetes mellitus or high serum glucose at presentation. In this subgroup, $97 \%$ of patients with diabetes achieved clinical cure after treatment with TGC compared with $74 \%$ after treatment with LEV (difference of 22.9; 95\% CI, 4.8 - 39.9). The reason for this difference and the clinical significance are unknown. A smaller difference in favor of TGC also was observed in patients with bacteremia and a history of previous antibiotic failure. Among these latter patients, clinical cure rates with TGC therapy were approximately $12 \%$ to $14 \%$ higher compared with LEV therapy, but this difference was not statistically significant. In 2 other subgroups (Fine score category of III - V and renal insufficiency) clinical cure rates were at least 8 percentage points higher following TGC therapy versus LEV therapy. It also is noteworthy that TGC-treated patients with at least 2 clinical instability criteria achieved a 90\% clinical cure rate, similar to the overall cure rate, although this may just reflect the fact that patients who required hospitalization had good responses to this treatment. In the c-mITT population, differences between the 2 treatment groups were less apparent.

A retrospective analysis of elderly patients with lower respiratory tract infections confirmed that many of these risk factors are linked with a more severe and complicated disease course [7]. The exploratory analysis presented herein utilized many of these previously identified prognostic risk factors in order to assess whether clinical outcome differed following TGC therapy or LEV therapy. Our analysis revealed that, despite the presence of risk factors suggestive of more severe illness and increased risk of death, TGC therapy was clinically effective across the severity spectrum of hospitalized adult patients with CAP, often achieving higher cure rates compared with the commonly prescribed fluoroquinolone. An imbalance in all-cause mortality has been observed in the phase 3 and 4 TGC clinical program overall [25] but with substantial differences among evaluated infection types. Within the CAP trials, the number of deaths were similar in $12 / 424(2.8 \%)$ and $11 / 422(2.6 \%)$ in the TGC and LEV treatment groups, respectively, with no difference in all-cause mortality rate (risk difference of $0.2 ; 95 \% \mathrm{CI}$, 2.0 - 2.4) [26].

The findings of our risk factor analysis are limited, as this is a post hoc analysis of previously pooled data [19]; the original studies were not powered for comparisons between subpopulations. Most of the analyses were planned as sensitivity/exploratory rather than primary analyses. While additional studies are needed to confirm these observations, the more consistent efficacy and slightly higher cure rates of TGC therapy compared with LEV therapy across individual risk factor subgroups were notable. An additional limitation of these findings was the relatively low number of $\mathrm{CE}$ patients with certain risk factors (e.g., prior antibiotic failure, altered mental status), which resulted in large CIs for the treatment difference, making interpretation of the results difficult. 
Table 2. Clinical Response at Test of Cure Assessment by Risk Factor ${ }^{\mathrm{a}}$

\begin{tabular}{|c|c|c|c|c|c|c|}
\hline \multirow[b]{3}{*}{ Risk Factor } & \multicolumn{6}{|c|}{ Study Population } \\
\hline & \multicolumn{3}{|c|}{$\mathbf{C E}$} & \multicolumn{3}{|c|}{ c-mITT } \\
\hline & $\begin{array}{l}\text { Tigecycline, } \\
\text { n (\%) }\end{array}$ & $\begin{array}{l}\text { Levofloxacin, } \\
\text { n (\%) }\end{array}$ & $\begin{array}{l}\text { Tigecycline - Levofloxacin, } \\
\text { \% Difference }(95 \% \text { CI) }\end{array}$ & $\begin{array}{l}\text { Tigecycline, } \\
\text { n (\%) }\end{array}$ & $\begin{array}{l}\text { Levofloxacin, } \\
\text { n (\%) }\end{array}$ & $\begin{array}{l}\text { Tigecycline - Levofloxacin, } \\
\% \text { Difference }(95 \% \text { CI })^{\mathrm{b}}\end{array}$ \\
\hline \multicolumn{7}{|l|}{ Overall } \\
\hline Cure & $253(89.7)$ & $252(86.3)$ & $3.4(-2.2-9.1)$ & $319(81.0)$ & $321(79.7)$ & $1.3(-4.5-7.1)$ \\
\hline Failure & $29(10.3)$ & $40(13.7)$ & & $45(11.4)$ & $57(14.1)$ & \\
\hline Indeterminate outcome & - & - & & $30(7.6)$ & $25(6.2)$ & \\
\hline \multicolumn{7}{|l|}{ Aged $\geq 65$ Years } \\
\hline Cure & $73(88.0)$ & $77(81.9)$ & $6.0(-5.7-17.2)$ & $89(77.4)$ & $91(77.8)$ & $-0.4(-11.7-10.9)$ \\
\hline Failure & $10(12.0)$ & $17(18.1)$ & & $13(11.3)$ & $19(16.2)$ & \\
\hline Indeterminate outcome & - & - & & $13(11.3)$ & $7(6.0)$ & \\
\hline \multicolumn{7}{|l|}{ Prior Antibiotic Failure } \\
\hline Cure & $9(81.8)$ & $14(70.0)$ & $11.8(-26.3-40.4)$ & $46(79.3)$ & $55(76.4)$ & $2.9(-12.8-17.8)$ \\
\hline Failure & $2(18.2)$ & $6(30.0)$ & & $9(15.5)$ & $15(20.8)$ & \\
\hline Indeterminate outcome & - & - & & $3(5.2)$ & $2(2.8)$ & \\
\hline \multicolumn{7}{|l|}{ Bacteremia } \\
\hline Cure & $21(84.0)$ & $14(70.0)$ & $14.0(-13.1-40.6)$ & $23(74.2)$ & $18(58.1)$ & $16.1(-9.4-39.1)$ \\
\hline Failure & $4(16.0)$ & $6(30.0)$ & & $6(19.4)$ & $9(29.0)$ & \\
\hline Indeterminate outcome & - & - & & $2(6.5)$ & $4(12.9)$ & \\
\hline \multicolumn{7}{|l|}{ Multilobar Disease at Baseline } \\
\hline Cure & $66(82.5)$ & $58(80.6)$ & $1.9(-11.2-15.4)$ & $89(74.8)$ & $74(73.3)$ & $1.5(-10.5-13.8)$ \\
\hline Failure & $14(17.5)$ & $14(19.4)$ & & $19(16.0)$ & $18(17.8)$ & \\
\hline Indeterminate outcome & - & - & & $11(9.2)$ & $9(8.9)$ & \\
\hline \multicolumn{7}{|l|}{ COPD } \\
\hline Cure & $26(81.3)$ & $23(76.7)$ & $4.6(-17.7-26.8)$ & $29(65.9)$ & $28(68.3)$ & $-2.4(-23.0-18.7)$ \\
\hline Failure & $6(18.8)$ & $7(23.3)$ & & $8(18.2)$ & $9(22.0)$ & \\
\hline Indeterminate outcome & - & - & & $7(15.9)$ & $4(9.8)$ & \\
\hline \multicolumn{7}{|l|}{ Hypoxemia } \\
\hline Cure & $59(88.1)$ & $62(82.7)$ & $5.4(-7.7-17.9)$ & $77(77.8)$ & $82(75.9)$ & $1.9(-10.4-13.8)$ \\
\hline Failure & $8(11.9)$ & $13(17.3)$ & & $11(11.1)$ & $14(13.0)$ & \\
\hline Indeterminate outcome & - & - & & $11(11.1)$ & $12(11.1)$ & \\
\hline \multicolumn{7}{|c|}{ Renal Insufficiency or BUN $>19.6 \mathrm{mg} / \mathrm{dL}$ or Urea $>7 \mathrm{mmol} / \mathrm{L}$} \\
\hline Cure & $85(86.7)$ & $79(78.2)$ & $8.5(-2.9-19.6)$ & $102(81.0)$ & $97(75.8)$ & $5.2(-5.5-15.7)$ \\
\hline Failure & $13(13.3)$ & $22(21.8)$ & & $15(11.9)$ & $24(18.8)$ & \\
\hline Indeterminate outcome & - & - & & $9(7.1)$ & $7(5.5)$ & \\
\hline \multicolumn{7}{|c|}{ Diabetes or Glucose $>13.9 \mathrm{mmol} / \mathrm{L}$} \\
\hline Cure & $35(97.2)$ & $29(74.4)$ & $22.9(4.8-39.9)$ & $41(83.7)$ & $41(71.9)$ & $11.7(-5.8-27.9)$ \\
\hline Failure & $1(2.8)$ & $10(25.6)$ & & $3(6.1)$ & $12(21.1)$ & \\
\hline Indeterminate outcome & - & - & & $5(10.2)$ & $4(7.0)$ & \\
\hline
\end{tabular}


(Table 2) contd.....

\begin{tabular}{|c|c|c|c|c|c|c|}
\hline \multirow[b]{3}{*}{ Risk Factor } & \multicolumn{6}{|c|}{ Study Population } \\
\hline & \multicolumn{3}{|c|}{$\mathbf{C E}$} & \multicolumn{3}{|c|}{ c-mITT } \\
\hline & $\begin{array}{l}\text { Tigecycline, } \\
\text { n (\%) }\end{array}$ & $\begin{array}{l}\text { Levofloxacin, } \\
\text { n (\%) }\end{array}$ & $\begin{array}{l}\text { Tigecycline - Levofloxacin, } \\
\text { \% Difference }(95 \% \text { CI) }\end{array}$ & $\begin{array}{l}\text { Tigecycline, } \\
\text { n (\%) }\end{array}$ & $\begin{array}{l}\text { Levofloxacin, } \\
\text { n (\%) }\end{array}$ & $\begin{array}{l}\text { Tigecycline - Levofloxacin, } \\
\% \text { Difference }(95 \% \text { CI })^{\mathrm{b}}\end{array}$ \\
\hline \multicolumn{7}{|l|}{ Alcohol Abuse } \\
\hline Cure & $24(85.7)$ & $23(85.2)$ & $0.5(-21.2-22.5)$ & $27(79.4)$ & $27(81.8)$ & $-2.4(-23.1-18.7)$ \\
\hline Failure & $4(14.3)$ & $4(14.8)$ & & $4(11.8)$ & $5(15.2)$ & \\
\hline Indeterminate outcome & - & - & & $3(8.8)$ & $1(3.0)$ & \\
\hline \multicolumn{7}{|l|}{ Altered Mental Status } \\
\hline Cure & $5(71.4)$ & $7(87.5)$ & $-16.1(-58.9-31.0)$ & $6(66.7)$ & $8(88.9)$ & $-22.2(-59.5-23.1)$ \\
\hline Failure & $2(28.6)$ & $1(12.5)$ & & $2(22.2)$ & $1(11.1)$ & \\
\hline Indeterminate outcome & - & - & & $1(11.1)$ & $0(0)$ & \\
\hline \multicolumn{7}{|c|}{ WBC Count $>30 \times 10^{9} / \mathrm{L}$ or $<4 \times 10^{9} / \mathrm{L}$} \\
\hline Cure & $10(76.9)$ & $11(73.3)$ & $3.6(-32.1-36.7)$ & $13(65.0)$ & $13(68.4)$ & $-3.4(-33.5-27.7)$ \\
\hline Failure & $3(23.1)$ & $4(26.7)$ & & $3(15.0)$ & $4(21.1)$ & \\
\hline Indeterminate outcome & - & - & & $4(20.0)$ & $2(10.5)$ & \\
\hline \multicolumn{7}{|l|}{ CURB-65 Score $\geq 2$} \\
\hline Cure & $72(85.7)$ & $82(82.8)$ & $2.9(-8.9-14.1)$ & $88(76.5)$ & $96(79.3)$ & $-2.8(-14.0-8.3)$ \\
\hline Failure & $12(14.3)$ & $17(17.2)$ & & $14(12.2)$ & $19(15.7)$ & \\
\hline Indeterminate outcome & - & - & & $13(11.3)$ & $6(5.0)$ & \\
\hline \multicolumn{7}{|l|}{ Fine Score Category III-V } \\
\hline Cure & $125(89.3)$ & $115(80.4)$ & $8.9(-0.1-17.7)$ & $149(80.1)$ & $144(76.6)$ & $3.5(-5.2-12.2)$ \\
\hline Failure & $15(10.7)$ & $28(19.6)$ & & $22(11.8)$ & $33(17.6)$ & \\
\hline Indeterminate outcome & - & - & & $15(8.1)$ & $11(5.9)$ & \\
\hline \multicolumn{7}{|c|}{ At Least 2 Clinical Instability Criteria } \\
\hline Cure & $207(90.0)$ & $198(86.1)$ & $3.9(-2.4-10.2)$ & $252(80.5)$ & $247(77.9)$ & $2.6(-4.0-9.1)$ \\
\hline Failure & $23(10.0)$ & $32(13.9)$ & & $36(11.5)$ & $46(14.5)$ & \\
\hline Indeterminate outcome & - & - & & $25(8.0)$ & $24(7.6)$ & \\
\hline \multicolumn{7}{|l|}{ Higher Risk of Mortality } \\
\hline Cure & $188(89.5)$ & $152(81.3)$ & $8.2(0.9-15.7)$ & $223(80.8)$ & $193(76.0)$ & $4.8(-2.5-12.1)$ \\
\hline Failure & $22(10.5)$ & $35(18.7)$ & & $34(12.3)$ & $44(17.3)$ & \\
\hline Indeterminate outcome & - & - & & $19(6.9)$ & $17(6.7)$ & \\
\hline
\end{tabular}

CE: clinically evaluable; c-mITT: clinical modified intention to treat; COPD: chronic obstructive pulmonary disease; BUN: blood urea nitrogen; WBC: white blood cell.

${ }^{a}$ Clinical cure was defined as all signs and symptoms of pneumonia improved or resolved, chest radiographs improved or not worse, no further antibiotic therapy necessary for treatment of pneumonia and no appearance of new signs and symptoms of pneumonia. Clinical failure was defined as persistence or worsening in signs and symptoms of the acute process, failure to show improvement in clinical findings, initial improvement in signs and symptoms followed by clinically significant worsening before test of cure assessment, additional necessary antimicrobial therapy for pneumonia, progression of chest radiograph abnormalities, death after study day 2 due to pneumonia or death due to a treatmentrelated adverse event.

Indeterminate outcome (clinically modified intention to treat population only) was defined as the patient was lost to follow-up, or died within 2 days after the first dose of study drug for any reason other than a treatment-related adverse event or died after 2 days because of non-infection-related reasons or infection other than pneumonia (as judged by the investigator).

${ }^{b} 95 \%$ confidence intervals (CIs) for overall differences were calculated using the normal approximation method with continuity correction. $95 \%$ CIs by risk factor differences were calculated using the Wilson score method with continuity correction. Unadjusted risk differences and CIs are presented.

Severity of illness, risk of mortality and consideration of the most common causative organisms, including resistant strains, are the cornerstones of current treatment guidelines for the management of CAP and the basis on which empiric antimicrobial selection (monotherapy $v s$ combination therapy) is suggested $[1,3,17,18,27]$. For hospitalized patients who do not require admission to an intensive care unit, current guidelines recommend either an extendedspectrum cephalosporin with or without an added macrolide, a beta-lactam/beta-lactamase inhibitor combination with or without an added macrolide or monotherapy with a newer fluoroquinolone $[1,3,17,18,27]$.

Despite the plethora of antibiotics currently available, treatment of CAP in the hospitalized patient continues to be 
Table 3. Mortality Rates by Risk Factor (Modified Intention to Treat Population)

\begin{tabular}{|l|c|c|}
\hline \multicolumn{1}{|c|}{ Risk Factor } & Tigecycline, $\mathbf{n}(\%)$ & Levofloxacin, $\mathbf{n}(\%)$ \\
\hline \hline Overall & $12(2.8)$ & $11(2.6)$ \\
\hline Aged $\geq 65$ years & $8(6.6)$ & $5(4.1)$ \\
\hline Prior antibiotic failure & $2(3.2)$ & $1(1.4)$ \\
\hline Bacteremia & $1(3.1)$ & $1(3.2)$ \\
\hline Multilobar disease at baseline & $8(6.4)$ & $7(6.6)$ \\
\hline COPD & $5(10.2)$ & $3(7.0)$ \\
\hline Hypoxemia & $4(3.8)$ & $5(4.4)$ \\
\hline Renal insufficiency or BUN $>19.6 \mathrm{mg} / \mathrm{dL}$ or urea $>7 \mathrm{mmol} / \mathrm{L}$ & $4(2.9)$ & $4(3.0)$ \\
\hline Diabetes or glucose $>13.9 \mathrm{mmol} / \mathrm{L}$ & $1(1.8)$ & $2(3.3)$ \\
\hline Alcohol abuse & $1(2.9)$ & $2(6.1)$ \\
\hline Altered mental status & $2(22.2)$ & 0 \\
\hline WBC count $>30 \mathrm{x} 10^{9} / \mathrm{L}$ or $<4 \mathrm{x} 10^{9} / \mathrm{L}$ & $1(4.8)$ & $1(5.3)$ \\
\hline Higher risk of mortality & $12(4.1)$ & $10(3.7)$ \\
\hline CE: clinically evaluable; c-mITT: clinical modified intention to treat; COPD: chronic obstructive pulmonary disease; BUN: blood urea nitrogen; WBC: white blood cell. \\
\hline
\end{tabular}

challenging, largely owing to rising resistance rates [4,6]. In an effort to optimize desired clinical response and minimize or prevent negative outcomes, a number of prognostic risk factors that significantly increase the risk of mortality have previously been identified, including male gender, hypothermia, systolic hypotension, tachypnea, diabetes mellitus, neoplastic diseases, neurologic disease, bacteremia, leukopenia and multilobar pulmonary infiltrates [9]. Based on these observations, the Fine pneumonia severity index and CURB-65 scoring system were developed to help clinicians determine the appropriate place of management based on mortality risk [11,12].

\section{CONCLUSIONS}

This pooled analysis provides evidence that TGC therapy was clinically effective in hospitalized patients with CAP with a number of risk factors for poor outcome, including the elderly (those aged $\geq 65$ years) and those with varied baseline clinical presentation and comorbidities. Risk factor assessment can be used to predict clinical failure in patients with CAP and to improve the efficiency of pneumonia management. TGC therapy may be an option for the treatment of hospitalized patients with CAP, including those with risk factors for poor outcome.

\section{CONFLICT OF INTEREST}

$\mathrm{ND}, \mathrm{CAC}$ and NC are full-time employees of Pfizer Inc. HG and DS were employees of Pfizer Inc at the time the study was conducted.

\section{ACKNOWLEDGEMENTS}

These studies and analyses were sponsored by Wyeth Research, which was acquired by Pfizer Inc in November 2009. All authors participated in the study design, analysis and interpretation of the data. Editorial support in the preparation and submission of this manuscript was provided by Hessamedin Alimohammadi of Upside Endeavors, LLC (Sanatoga) and Patricia Fonseca and Charlotte Kenreigh of
UBC Scientific Solutions and was funded by Pfizer Inc. Additional statistical support was provided by Tracy Franklin of Quintiles and was funded by Pfizer Inc. The authors thank Gary Dukart (formerly of Wyeth Research) and members of the 308 and 313 Study Groups for their valuable involvement in these studies.

\section{REFERENCES}

[1] Bartlett JG, Dowell SF, Mandell LA, File TM Jr, Musher DM, Fine MJ. Practice guidelines for the management of communityacquired pneumonia in adults. Clin Infect Dis 2000; 31:347-82.

[2] Halm EA, Teirstein AS. Clinical practice. Management of community-acquired pneumonia. N Engl J Med 2002; 347: 203945 .

[3] Mandell LA, Bartlett JG, Dowell SF, File TM Jr, Musher DM, Whitney C. Infectious Diseases Society of America. Update of practice guidelines for the management of community-acquired pneumonia in immunocompetent adults. Clin Infect Dis 2003; 37: 1405-33.

[4] File TM Jr. Clinical implications and treatment of multiresistant Streptococcus pneumoniae pneumonia. Clin Microbiol Infect 2006; 12: 31-41.

[5] Lynch JP III, Zhanel GG. Escalation of antimicrobial resistance among Streptococcus pneumoniae: implications for therapy. Semin Respir Crit Care Med 2005; 26: 575-616.

[6] Bradley SF. Staphylococcus aureus pneumonia: emergence of MRSA in the community. Semin Respir Crit Care Med 2005; 26: 643-9.

[7] Gil DR, Undurraga PA, Saldías PF, Jiménez PP, Barros MM. Prognostic factors and outcome of community-acquired pneumonia in hospitalized adult patients. Rev Med Chil 2006; 134: 1357-66.

[8] Hak E, Bont J, Hoes AW, Verheij TJ. Prognostic factors for serious morbidity and mortality from community-acquired lower respiratory tract infections among the elderly in primary care. Fam Pract 2005; 22: 375-80.

[9] Fine MJ, Smith MA, Carson CA, et al. Prognosis and outcomes of patients with community-acquired pneumonia: a meta-analysis. JAMA 1996; 275: 134-41.

[10] Poe RH, Wahl GW, Qazi R, Kallay MC, Utell MJ, Morrow GR. Predictors of mortality in the immunocompromised patient with pulmonary infiltrates. Arch Intern Med 1986; 146: 1304-8.

[11] Fine MJ, Auble TE, Yealy DM, et al. A prediction rule to identify low-risk patients with community-acquired pneumonia. N Engl J Med 1997; 336: 243-50. 
[12] Lim WS, van der Eerden MM, Laing R, et al. Defining community acquired pneumonia severity on presentation to hospital: an international derivation and validation study. Thorax 2003; 58: 377-82.

[13] Zhanel GG, Karlowsky JA, Rubinstein E, Hoban DJ. Tigecycline: a novel glycylcycline antibiotic. Expert Rev Anti Infect Ther 2006; 4: 9-25.

[14] Squires RA, Postier RG. Tigecycline for the treatment of infections due to resistant Gram-positive organisms. Expert Opin Investig Drugs 2006; 15: 155-62.

[15] Babinchak T, Ellis-Grosse E, Dartois N, Rose GM, Loh E, Tigecycline 301 and 306 Study Groups. The efficacy and safety of tigecycline for the treatment of complicated intra-abdominal infections: analysis of pooled clinical trial data. Clin Infect Dis 2005; 41: S354-67.

[16] Ellis-Grosse EJ, Babinchak T, Dartois N, Rose G, Loh E, Tigecycline 300 and 305 cSSSI Study Groups. The efficacy and safety of tigecycline in the treatment of skin and skin-structure infections: results of 2 double-blind phase 3 comparison studies with vancomycin-aztreonam. Clin Infect Dis 2005; 41: S341-53.

[17] File TM Jr, Garau J, Blasi F, et al. Guidelines for empiric antimicrobial prescribing in community-acquired pneumonia. Chest 2004; 125: 1888-901.

[18] Woodhead M, Blasi F, Ewig S, et al. European Society of Clinical Microbiology and Infectious Diseases. Guidelines for the management of adult lower respiratory tract infections. Eur Respir J 2005; 26: 1138-80.

[19] Tanaseanu C, Bergallo C, Teglia O, et al. Integrated results of 2 phase 3 studies comparing tigecycline and levofloxacin in community-acquired pneumonia. Diagn Microbiol Infect Dis 2008; 61: 329-38.
[20] van de Garde EM, Souverein PC, van den Bosch JM, Deneer VH, Goettsch WG, Leufkens HG. Prior outpatient antibacterial therapy as prognostic factor for mortality in hospitalized pneumonia patients. Respir Med 2006; 100: 1342-8.

[21] Molinos L, Clemente MG, Miranda B, et al. Community-acquired pneumonia in patients with and without chronic obstructive pulmonary disease. J Infect 2009; 58: 417-24.

[22] Ruiz M, Ewig S, Torres A, et al. Severe community-acquired pneumonia. Risk factors and follow-up epidemiology. Am J Respir Crit Care Med 1999; 160: 923-9.

[23] Menéndez R, Torres A, Rodríguez de Castro F, et al. Reaching stability in community-acquired pneumonia: the effects of the severity of disease, treatment, and the characteristics of patients. Clin Infect Dis 2004; 39: 1783-90.

[24] Ramirez JA, Vargas S, Ritter GW, et al. Early switch from intravenous to oral antibiotics and early hospital discharge: prospective observational study of 200 consecutive patients with community-acquired pneumonia. Arch Intern Med 1999; 159: 2449-54.

[25] McGovern P, Wible M, El-Tahtawy A, Biswas P, Meyer D. Mortality imbalance in the tigecycline phase 3 and 4 clinical trials. In: 40th Annual Congress of the Society of Critical Care Medicine. San Diego, CA, 2011.

[26] Wyeth Pharmaceuticals Inc. (2011) Tygacil $^{\mathbb{Q}}$ [tigecycline] for injection for intravenous use. Full prescribing information. URL http://labeling.pfizer.com/showlabeling.aspx?id=491 [Accessed on July 13 2012].

[27] Niederman MS, Mandell LA, Anzueto A, et al. Guidelines for the management of adults with community-acquired pneumonia: diagnosis, assessment of severity, antimicrobial therapy, and prevention. Am J Respir Crit Care Med 2001; 163: 1730-54.

(C) Dartois et al.; Licensee Bentham Open

This is an open access article licensed under the terms of the Creative Commons Attribution Non-Commercial License (http://creativecommons.org/licenses/by-nc/3.0/) which permits unrestricted, non-commercial use, distribution and reproduction in any medium, provided the work is properly cited. 